ARTICLE

DOI: $10.1038 / \mathrm{s} 41467-017-00582-9$

\title{
Ultrathin high band gap solar cells with improved efficiencies from the world's oldest photovoltaic material
}

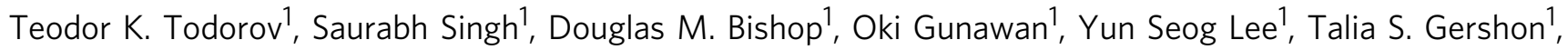
Kevin W. Brew ${ }^{1}$, Priscilla D. Antunez ${ }^{1} \&$ Richard Haight ${ }^{1}$

Selenium was used in the first solid state solar cell in 1883 and gave early insights into the photoelectric effect that inspired Einstein's Nobel Prize work; however, the latest efficiency milestone of $5.0 \%$ was more than 30 years ago. The recent surge of interest towards highband gap absorbers for tandem applications led us to reconsider this attractive $1.95 \mathrm{eV}$ material. Here, we show completely redesigned selenium devices with improved back and front interfaces optimized through combinatorial studies and demonstrate record open-circuit voltage $\left(V_{O C}\right)$ of $970 \mathrm{mV}$ and efficiency of $6.5 \%$ under $1 \mathrm{Sun}$. In addition, Se devices are air-stable, non-toxic, and extremely simple to fabricate. The absorber layer is only $100 \mathrm{~nm}$ thick, and can be processed at $200{ }^{\circ} \mathrm{C}$, allowing temperature compatibility with most bottom substrates or sub-cells. We analyze device limitations and find significant potential for further improvement making selenium an attractive high-band-gap absorber for multijunction device applications.

\footnotetext{
${ }^{1}$ IBM Thomas J. Watson Research Center, 1101 Kitchawan Road, Yorktown Heights, NY 10598, USA. Correspondence and requests for materials should be addressed to T.K.T. (email: tktodoro@us.ibm.com)
} 
n 1873, Willoughby Smith discovered the photoconductivity of selenium $(\mathrm{Se})^{1}$. Ten years later, Charles Fritts created the first solid solar cells by coating metal foils with selenium and thin layers of gold. Puzzled by the peculiar current behavior of his cell under illumination he wondered what yet unthought-of properties this method could reveal and where its limit would be $\mathrm{e}^{2}$. The photoelectric effect and other fundamental phenomena observed in this early semiconductor propagated through modern science and technology, leading to Einstein's Nobel Prize work ${ }^{3}$, the photocopy machine, sensors, and rectifiers, among other technologies ${ }^{4}, 5$. Selenium research declined in the wake of the rapidly expanding silicon microelectronic industry which offered a highquality material with a band gap $\left(E_{\mathrm{g}}\right)$ more suitable for a singlejunction solar cell. The development of silicon for integrated circuits provided both the science and technology that propelled silicon photovoltaic (PV) device efficiency from $\sim 6 \%$ in 1954 to $26.6 \%$ today $^{6,7}$. By contrast, Se achieved $<1 \%$ in the earliest demonstrations and culminated with $5.0 \%$ in the 1980 's ${ }^{2}, 6$. Since then, the silicon PV industry has grown, reducing production costs and module prices, while achieving a champion module efficiency of $24.1 \%{ }^{8}, 9$. While improved device structure, material quality and passivation have enabled increased conversion efficiency, future improvements in these areas will provide diminishing improvements as we continue to approach the practical limits for Si single junction. Tandem solar cell architectures with multiple band gaps offer the most realistic path to higher PV efficiencies surpassing the limitations of single junctions.

Until recently, multi-junction cells have been limited to low-efficiency amorphous silicon and expensive III-V semiconductor photovoltaic materials. These devices require sophisticated solar tracking concentrator systems and have been less practical for mainstream deployment in comparison with planar Si modules. For many years, the main challenge for creating efficient and low cost tandem PV devices for large-area applications has been the lack of an efficient high- $E_{\mathrm{g}}$ top cell that is process compatible for fabrication on a lower $E_{\mathrm{g}}$ absorber. Recently, metal-organic hybrid perovskite materials have reinvigorated the research of planar tandem photovoltaic devices as they offered high-efficiency solar cells with high $(>1.55 \mathrm{eV})$ tunable band gaps that can be processed at low temperatures ${ }^{10-13}$. However, concerns about the long-term stability of these compounds, as well as their heavy metal content, have motivated the search for more stable and less toxic alternatives.

Trigonal selenium has a reported $E_{\mathrm{g}}$ between 1.83 and $2 \mathrm{eV}$ depending on fabrication conditions ${ }^{14}$, 15 . It can be processed at a range of temperatures below its melting point of $220^{\circ} \mathrm{C}$, making it an attractive candidate for top absorber in monolithic tandem or even triple-junction photovoltaic device. However, the last efficiency record of 5.0\% for a Se solar cell reported in 1985 has remained unchanged for more than 30 years ${ }^{16}$. This champion cell utilized n-type $\mathrm{TiO}_{2}$, deposited on $\mathrm{SnO}_{2}: \mathrm{F}$ (FTO) coated glass and p-type Se followed by gold contact. This structure is similar to some modern hybrid perovskite solar cells without an advanced hole-transport layer ${ }^{17}$. Some recent works explored additional elements, such as mesoporous $\mathrm{TiO}_{2}$ in combination with poly(3-hexylthiophene-2,5-diyl) (P3HT) and poly(3,4-ethylenedioxythiophene)-poly(styrenesulfonate) (PEDOT:PSS) holetransport layers ${ }^{18}, 19$. However, these approaches have not yet achieved improved efficiency values.

In this work, we demonstrate a redesigned selenium device structure with three major advances over the previous art. First, we introduced a reliable inorganic $\mathrm{MoO}_{x}$ high-work-function hole-selective layer between the selenium and the gold back contact to reduce recombination and improve collection as has been demonstrated in both CdTe solar cells as well as other inorganic and organic photovoltaics ${ }^{20-22}$. Second, in order to increase the benefit from the back surface field and at the same time decrease material consumption and fabrication time, we drastically reduced the thickness of the selenium absorber to only $100 \mathrm{~nm}-20$ times less than the previous Se champion cell as well as typical chalcogenide absorbers such as copper indium gallium selenide (CIGS). Finally, a tunable band gap $\mathrm{Zn}_{x} \mathrm{Mg}_{1-x} \mathrm{O}$ $(\mathrm{ZnMgO})$ buffer based on state-of-the-art developments from the field of chalcogenide photovoltaics ${ }^{23}$ was optimized with combinatorial studies to produce a record open-circuit voltage $\left(V_{\mathrm{OC}}\right)$ of $969 \mathrm{mV}$. It is important to note that this voltage still has significant room for further improvement as it is almost $700 \mathrm{mV}$ below the Shockley-Queisser (SQ) limit for the band gap of Se $(1.95 \mathrm{eV})$.

\section{Results}

Device elements and their optimization. The fabrication of our superstrate Se solar cells is significantly simpler than other chalcogenide devices which require high temperature absorber treatments, and to some extent resembles the fabrication sequence of perovskite solar cells. The device structure in this study consists of glass/FTO/n-type buffer $\left(\mathrm{ZnMgO}\right.$ or $\left.\mathrm{TiO}_{2}\right) / \mathrm{Se} / \mathrm{MoO}_{x} / \mathrm{Au}$. A scanning electron microscopy (SEM) cross section of the champion device with $\mathrm{ZnMgO}$ buffer layer is shown in Fig. 1a.

Initial experiments utilized dense $\mathrm{TiO}_{2}$ electron-selective layers deposited by spray pyrolysis on commercial FTO glass substrates, a

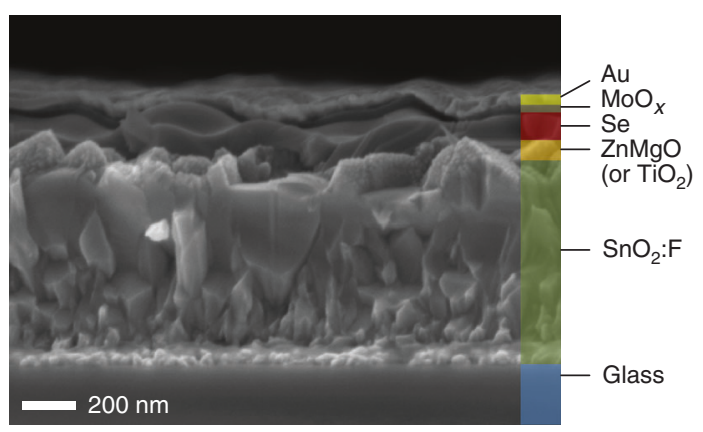

b

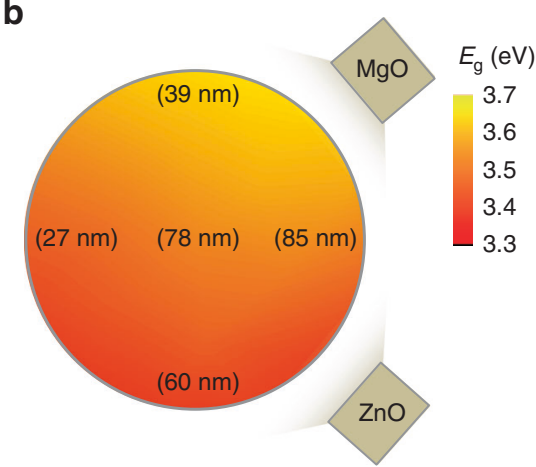

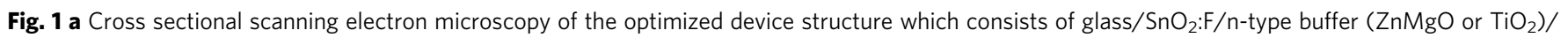
$\mathrm{Se} / \mathrm{MoO}_{x} / \mathrm{Au}$. Only 100-nm-thick Se absorber is used. b A schematic of combinatorial sputtering setup for accelerated studies on ZnMgO n-type buffer layers. A color map indicates the band gap $\left(E_{g}\right)$ of $\mathrm{ZnMgO}$ thin films measured by optical absorption spectra. The measured film thickness values in the map indicate a gradient of deposition rate 

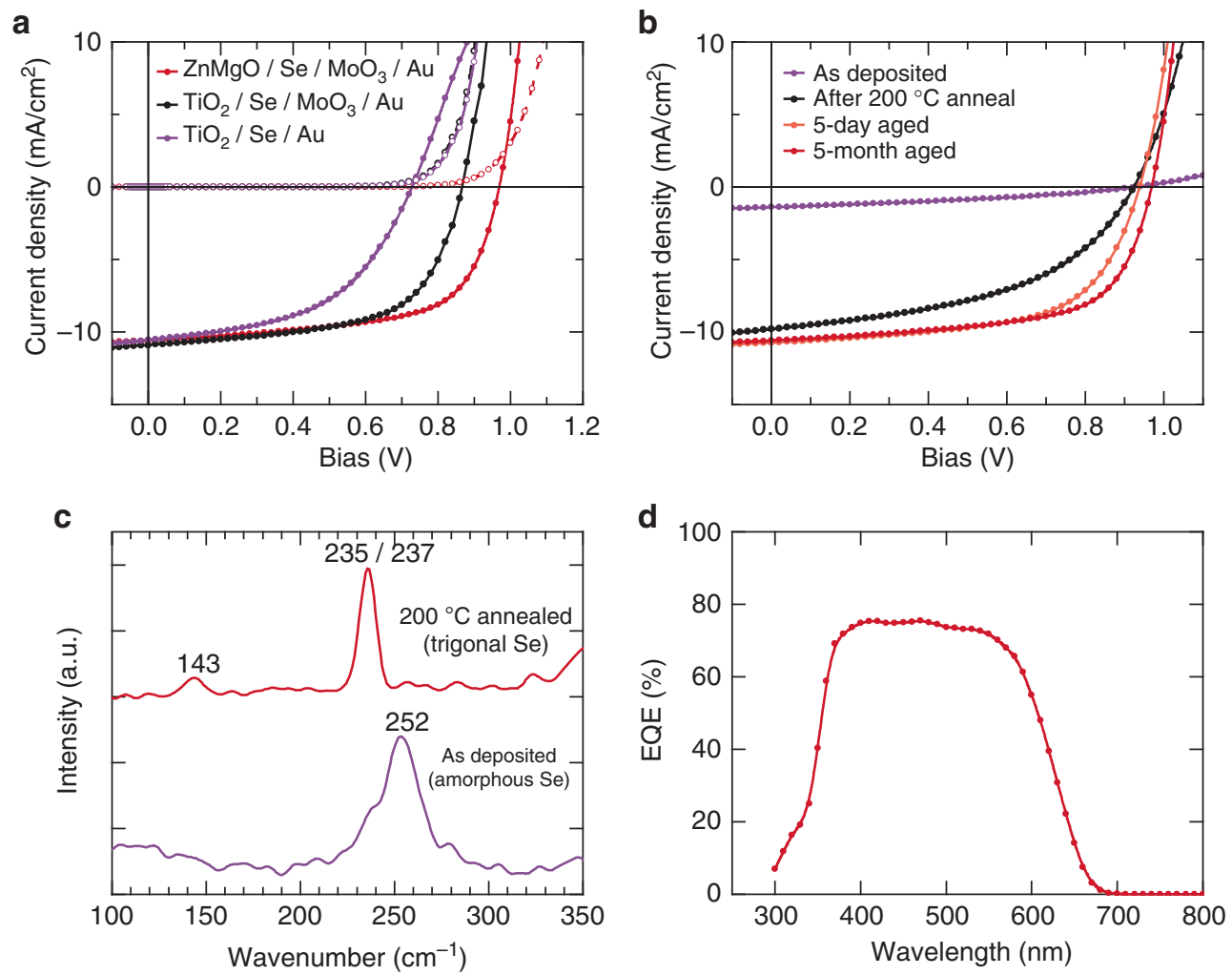

Fig. 2 a As-measured current-voltage ( $J-V$ ) characteristics of Se solar cell devices under dark (dashed lines) and illuminated (solid lines) condition, showing the effect of buffer and hole-transport layer. $\mathrm{ZnMgO} / \mathrm{Se} / \mathrm{MoO}_{x} / \mathrm{Au}, \mathrm{TiO}_{2} / \mathrm{Se} / \mathrm{MoO}_{x} / \mathrm{Au}$, and $\mathrm{TiO}_{2} / \mathrm{Se} / \mathrm{Au}$ devices are shown in red, black, and purple, respectively. $\mathbf{b}$ Illuminated $\mathrm{J}-\mathrm{V}$ plots of $\mathrm{ZnMgO} / \mathrm{Se} / \mathrm{MoO}_{x} / \mathrm{Au}$ devices with as-deposited $\mathrm{Se}$, annealed at $200{ }^{\circ} \mathrm{C}$, 5-day aged after annealing, and 5 -month aged after annealing Se are shown in purple, black, orange and red. c Raman spectra of as-deposited Se (purple) and annealed Se at $200{ }^{\circ} \mathrm{C}($ red). The

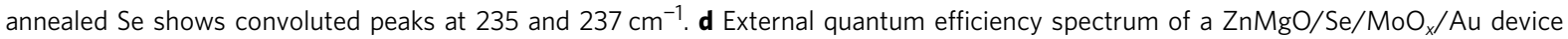

as is commonly done for dye-sensitized and perovskite solar cells $^{24}$. This layer served for the initial device structure optimization, including the $\mathrm{MoO}_{x}$ back contact layer that produced our first efficiency improvement (Fig. 2a).

The Se absorber was deposited by thermal evaporation which does not require high vacuum as Se evaporates readily at low temperature. The as-deposited selenium is red with a $E_{\mathrm{g}}$ of $2.17 \mathrm{eV}$ determined by UV-vis absorption spectroscopy and comprises mainly the amorphous phase. This phase gave very low efficiency (Fig. 2b), exhibited high resistivity and had poor collection at long wavelengths as evidenced by external quantum efficiency (EQE) suggesting significant recombination in the amorphous phase. Subsequent annealing at $200{ }^{\circ} \mathrm{C}$ for $2 \mathrm{~min}$ produced dark brown to gray samples correlated with conversion to trigonal selenium phase confirmed by Raman spectroscopy as shown in Fig. 2c. This also decreased the effective band gap of the absorber to about $1.95 \pm 0.04 \mathrm{eV}$ as determined from the Tauc plot in close agreement with the EQE derivative method using inflection of the EQE curve near the band edge (Fig. 2d). As with earlier works, we found that device performance increased with temperature up to about $200^{\circ} \mathrm{C}^{6}$ above which severe device deterioration occurred linked to loss of a conformal Se layer coverage due surface de-wetting near the Se melting point. To improve Se adhesion and uniformity, as has been previously demonstrated $^{6}$, a tellurium layer on the order of $1 \mathrm{~nm}$ was deposited on the buffer layer prior to Se deposition. Te adhesion layer was critical for obtaining functional devices as otherwise the Se layer becomes porous during annealing leading to shunting. Larger quantities of Te are expected to reduce the $E_{\mathrm{g}}$ and therefore could increase the efficiency in the typical AM1.5 spectrum, but were found to decrease performance in our testing due to lower shunt resistance which requires further investigation. Hall measurements were performed using a rotating parallel dipole line AC Hall system ${ }^{25}$ on a $105 \mathrm{~nm} \mathrm{Se} / \mathrm{ZnMgO} /$ glass sample annealed at $200{ }^{\circ} \mathrm{C}$ which yields a low carrier density of $2.8 \times 10^{12} \mathrm{~cm}^{-3}$ and mobility of $0.46 \mathrm{~cm}^{2} \mathrm{~V}^{-1} \mathrm{~s}^{-1}$. This should serve as a good estimate for the Se film characteristics as the standalone $\mathrm{ZnMgO}$ sheet resistance was too high to measure in our setup $(\sim>1 \mathrm{~T} \Omega$ per square). Compared to most PV absorbers the carrier density and mobility in these Se films is quite $\operatorname{low}^{26}$. Increasing the carrier density without significantly increasing recombination may be an effective means for future voltage improvements.

Functional devices were obtained with a selenium thickness range of $25-200 \mathrm{~nm}$ with highest performance found at about $100 \mathrm{~nm}$. While a thicker absorber is expected to increase the number of photons absorbed, particularly for wavelengths near the $E_{\mathrm{g}}$, this is counter acted by decreasing carrier collection for thicker samples due to the smaller effect of the back surface field, and the increasing resistance for thicker absorbers which further reduces the fill factor. At the $\mathrm{Se}$ band gap, $1.95 \mathrm{eV}$, the transmission through the FTO $+100 \mathrm{~nm}$ Se layer is only $16 \%$, suggesting that this thickness is sufficient to absorb most of the available photons when coupled with the additional benefit of reflective metal back contact. Remarkably, devices as thin as $25 \mathrm{~nm}$ were able to produce efficiencies in excess of $2.7 \%$. The transmission data for a solar cell fabricated following the same procedure of the record device without a gold back contact is shown in Supplementary Fig. 1.

The hole-selective $\mathrm{MoO}_{x}$ back layer (10-30 nm thick) and $\mathrm{Au}$ contacts (50-100 $\mathrm{nm}$ thick) were deposited by thermal evaporation. No additional flow of oxygen was used during the evaporation from $\mathrm{MoO}_{3}$ powder, and therefore it is expected that 

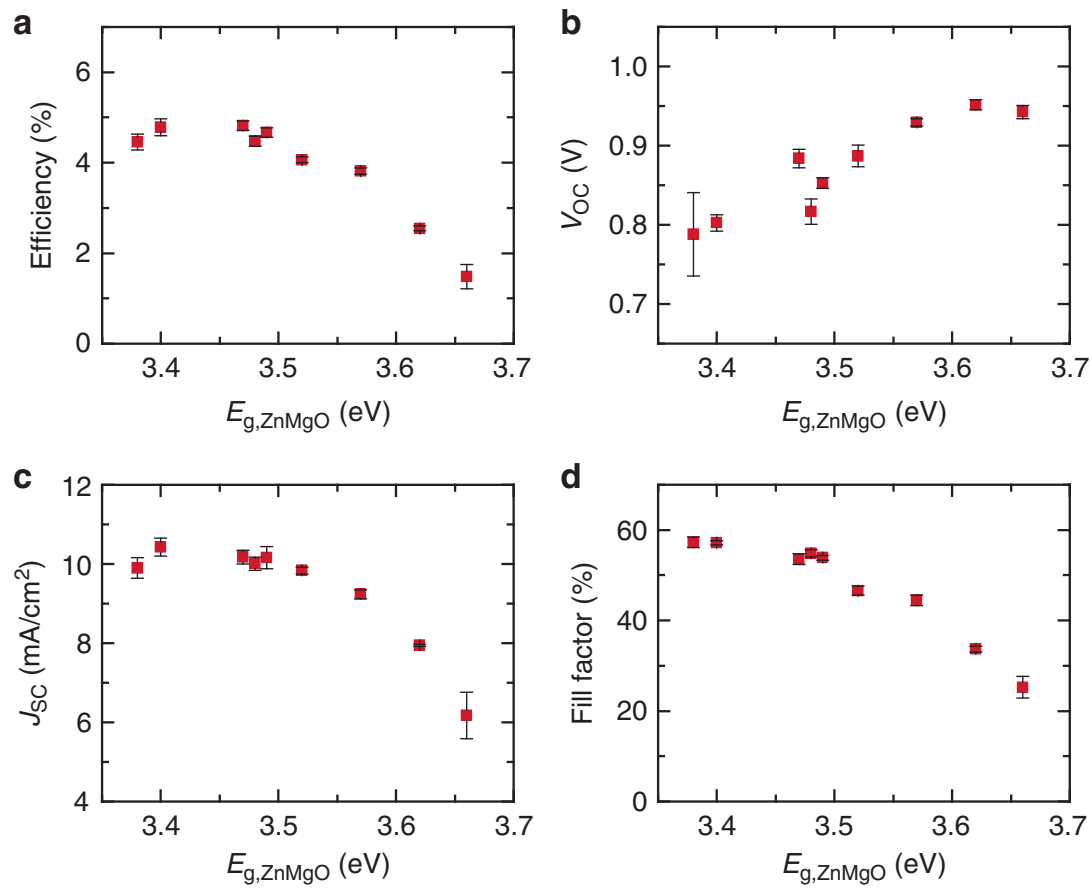

Fig. 3 Effects of band gap $\left(E_{g}\right)$ of $Z n M g O$ buffer layer on the photovoltaic characteristics. a Power conversion efficiency, b Open-circuit voltage ( $V_{O C}$ ), c Sort circuit current $\left(J_{S C}\right)$, and $\mathbf{d}$ fill factor of the $\mathrm{ZnMgO} / \mathrm{Se} / \mathrm{MoO}_{x} / \mathrm{Au}$ devices prepared by the combinatorial deposition process are plotted against measured $E_{\mathrm{g}}$ of $\mathrm{ZnMgO}$ layer. Square symbols and error bars indicate average values and standard deviations, respectively

oxygen vacancies in the deposited material will be present. This would result in modified work function of $\mathrm{MoO}_{x}$; however, this can vary with subsequent exposure to air $^{27}$ and requires further investigation. We found an optimal $\mathrm{MoO}_{x}$ thickness around $20 \mathrm{~nm}$. As can be seen in Fig. 2, the introduction of $\mathrm{MoO}_{x}$ produced an improvement in both the fill factor from 50.5 to $60.6 \%$ and the $V_{\text {OC }}$ from 728 to $866 \mathrm{mV}$. It is important to note that all cell parameters significantly improve in the first 5 days after fabrication followed by slow increase measured up to 5 months (Fig. 2b). One possible explanation for this performance improvement is the change of the properties of the $\mathrm{MoO}_{x}$ upon air exposure which has been linked to aging performance improvements in other systems using $\mathrm{MoO}_{x}$ layers ${ }^{27}$.

The wide band gap of the Se absorber puts additional constraints on the choice of optimal electron-selective contact or n-type buffer material. This layer must repel holes, which can be achieved by inducing downward band bending of the valence band while also allowing electrons to pass. A slight spike in the conduction band alignment can further create a slight barrier to recombination at the interface, while still low enough to allow current flow. The desired type-II band alignment can be difficult to achieve due to the difficulty finding buffer materials with conduction band positions above that of Se due to the high-band gap ${ }^{28}$.

Tunable buffers offer an opportunity to optimize valence and conduction band alignment with the absorber. One such buffer, $\mathrm{ZnMgO}$, is particularly attractive since its conduction band position can be tuned through the introduction of varying $\mathrm{Mg}$ doping. This material has been successfully used for improving the band alignment in CIGS- and polymer-based PV devices ${ }^{29,30}$. The $E_{\mathrm{g}}$ of $\mathrm{ZnO}$ and $\mathrm{MgO}$ are 3.3 and $7.8 \mathrm{eV}$, respectively. $\mathrm{ZnO}$ has a conduction band edge below that of Se, so the addition of low concentrations of $\mathrm{Mg}$ is expected to move the conduction edge upward, therefore reducing the magnitude of the cliff. This buffer/absorber interface also serves as electron-selective contact and the band bending helps repel the holes from the interface thus minimizing the surface recombination.
We used a simple confocal sputtering setup ${ }^{31}$ for accelerated combinatorial studies of $\mathrm{ZnMgO}$ buffer devices with different $[\mathrm{Zn}]:[\mathrm{Mg}]$ ratios as well as buffer thicknesses based on co-sputtering of mixed composition from separate $\mathrm{ZnO}$ and $\mathrm{MgO}$ sources, as depicted in Fig. 1b. The decreasing deposition rate with the distance from each source produced transverse gradients in $E_{\mathrm{g}}$ of $\mathrm{ZnMgO}$ and total thickness across an 8 inch diameter sample area. Figure 3 shows the device parameters obtained at indexed coordinates showed clear correlation between the $E_{\mathrm{g}}$ of the buffer layer and performance. While the $V_{\mathrm{OC}}$ continues to increase with the $E_{\mathrm{g}}$ of $\mathrm{ZnMgO}$, a trade-off is observed with increased series resistance resulting in a lower fill factor. Current-density vs. voltage characteristics of representative devices with various $\mathrm{ZnMgO}$ buffer layers and averaged series resistance values under 1-Sun illumination are shown in Supplementary Fig. 2. Optimal buffer thickness was determined to be in the range of $60-85 \mathrm{~nm}$ (Supplementary Fig. 3) with an optimal band gap of $3.4 \mathrm{eV}$ that corresponds to approximate composition of $\mathrm{Mg} /(\mathrm{Zn}+\mathrm{Mg})=0.1$ determined by deposition rate calibration in close agreement with literature data on the $\mathrm{ZnMgO}$ system optical properties ${ }^{23}$. A standard sputtering process with sample rotation was then developed to produce baseline buffer layers with noted optimal composition and thickness for further studies, enabling the current record-performance $\mathrm{ZnMgO}$ devices.

Femtosecond pump-probe ultraviolet photoelectron spectroscopy (fs-UPS) was employed to study the band alignments between $\mathrm{Se}$ and the buffers ${ }^{32,33}$. This technique has been described elsewhere (put references here). Briefly, correlated 40 fs pump $(3.1 \mathrm{eV})$ and probe $(26.35 \mathrm{eV})$ pulses were used to carry out UPS on Se and $\mathrm{ZnMgO} / \mathrm{Se}$ and $\mathrm{TiO}_{2} / \mathrm{Se}$ surfaces under flatband conditions. Band bending in the Se was extracted by comparing the energetic shifts of pumped and unpumped spectra. Figure 4a shows an overlay of the UPS spectra for Se and $\mathrm{ZnMgO}$ where the valence band maximum $\left(E_{\mathrm{VB}}\right)$ relative to the Fermi level $\left(E_{\mathrm{F}}\right)$ can be found from the well-established method of extrapolating the valence density of states to zero intensity. The Fermi level was determined in the standard fashion for UPS 
a

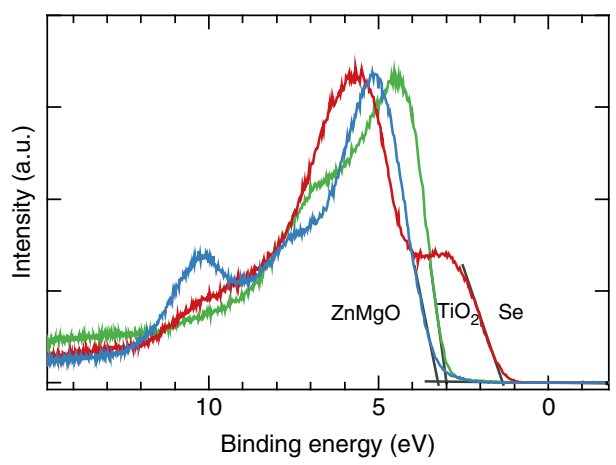

b

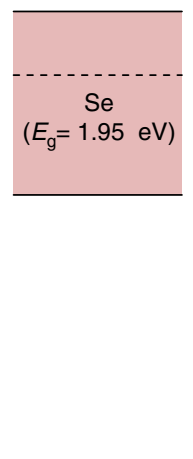

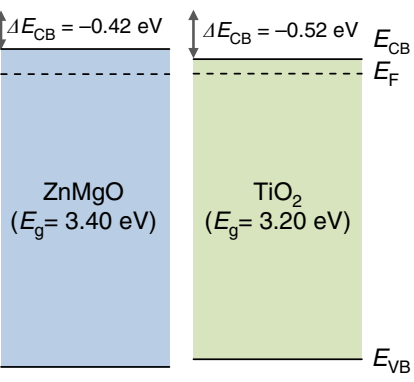

Fig. 4 a Femtosecond ultraviolet photoelectron spectroscopy (fs-UPS) spectra of Se (red), $\mathrm{TiO}_{2}$ (green), and $\mathrm{ZnMgO}$ (blue) under flat-band conditions. b Valence band and conduction band lineups extracted from the fs-UPS and optical absorption spectra

Table 1 Top performing Se devices

\begin{tabular}{|c|c|c|c|c|c|c|c|c|}
\hline Device & Efficiency (\%) & Fill factor (\%) & $V_{\text {oc }}(V)$ & $J_{S C}\left(\mathrm{~mA} \mathrm{~cm}^{-2}\right)$ & $n_{1}$ & $J_{01}\left(\mathrm{~A} \mathrm{~cm}^{-2}\right)$ & $R_{\mathrm{S}}\left(\Omega \mathrm{cm}^{2}\right)$ & $G_{\mathrm{sh}}\left(\mathrm{S} \mathrm{cm}^{-2}\right)$ \\
\hline $\mathrm{ZnMgO} / \mathrm{Se} / \mathrm{MoO}_{x} / \mathrm{Au}$ & 6.51 & 63.4 & 0.969 & 10.6 & $\begin{array}{l}2.78 \\
(2.23)\end{array}$ & $\begin{array}{l}1.09 \times 10^{-8} \\
\left(1.47 \times 10^{-7}\right)\end{array}$ & $\begin{array}{l}0.213 \\
(0.655)\end{array}$ & $\begin{array}{l}1.09 \times 10^{-8} \\
\left(1.58 \times 10^{-11}\right)\end{array}$ \\
\hline $\mathrm{TiO}_{2} / \mathrm{Se} / \mathrm{MoO}_{x} / \mathrm{Au}$ & 5.73 & 60.6 & 0.866 & 10.9 & $\begin{array}{l}3.14 \\
(1.93)\end{array}$ & $\begin{array}{l}1.94 \times 10^{-8} \\
\left(1.54 \times 10^{-8}\right)\end{array}$ & $\begin{array}{l}0.828 \\
(1.18)\end{array}$ & $\begin{array}{l}2.19 \times 10^{-8} \\
\left(1.06 \times 10^{-5}\right)\end{array}$ \\
\hline $\mathrm{TiO}_{2} / \mathrm{Se} / \mathrm{Au}$ & 3.88 & 50.5 & 0.728 & 10.5 & $\begin{array}{l}4.00 \\
(1.95)\end{array}$ & $\begin{array}{l}7.48 \times 10^{-6} \\
\left(1.59 \times 10^{-10}\right)\end{array}$ & $\begin{array}{l}6.255 \\
(1.15)\end{array}$ & $\begin{array}{l}2.63 \times 10^{-3} \\
\left(8.83 \times 10^{-6}\right)\end{array}$ \\
\hline SQ limit $\left(E_{g}=1.95 \mathrm{eV}\right)$ & 23.9 & 92.1 & 1.65 & 15.7 & 1 & $2.99 \times 10^{-30}$ & 0 & 0 \\
\hline
\end{tabular}

Statistics on device variation within a batch is shown in the SI. The single diode parameters in illuminated and dark conditions are also presented: ideality factor $\left(n_{1}\right)$, dark reverse saturation current $\left(J_{01}\right)$, series resistance $\left(R_{\mathrm{S}}\right)$ and shunt conductance $\left(G_{\mathrm{sh}}\right)$. The values with parentheses are extracted from dark current-voltage $(J-V)$ measurement. Shockley-Queisser $(S Q)$ limit calculated from refs. 36,37

measurements by measurement of a clean metal surface in electrical contact with the sample. The valence band maximum for the clean Se surface (seen in red) is found to be $1.28 \mathrm{eV}$ below $E_{\mathrm{F}}$, shown as $0 \mathrm{eV}$. A thin $\mathrm{ZnMgO}$ layer was deposited on top of the $\mathrm{Se}$ and is also shown in the spectrum in blue. The valence band offset for this heterojunction is $1.87 \mathrm{eV}$.

Once the valence band offset was determined using fs-UPS, the conduction band offset is calculated from the measurement of the band gaps of both the $\mathrm{Se}(1.95 \mathrm{eV})$ and $\mathrm{ZnMgO}(3.4 \mathrm{eV}$ determined from the Tauc plot of the optical absorption) and adding these values to the valence band maxima of Se and $\mathrm{ZnMgO}$ respectively. The determination of the valence band maximum was accurate to within $\pm 0.05 \mathrm{eV}$. The resulting measurement confirms a cliff-like band offset of $0.42 \mathrm{eV}$. Further increases in $[\mathrm{Mg}]$ should increase in the conduction band minimum of the $\mathrm{ZnMgO}$ and reduce the cliff offset which would further improve the $V_{\mathrm{OC}}$ of the $\mathrm{ZnMgO} / \mathrm{Se}$ devices; however, this produced an increased resistivity and a drop in the fill factor, resulting in lower efficiency in our devices. A useful comparison can be made with $\mathrm{TiO}_{2}$ as a buffer material. This is shown on the right side of Fig. $4 \mathrm{~b}$ schematic. The $\mathrm{TiO}_{2}$ valence band maximum is located $3.05 \mathrm{eV}$ below $E_{\mathrm{F}}$ and with a $E_{\mathrm{g}}$ of $3.2 \mathrm{eV}$ this would locate the conduction band minimum $0.52 \mathrm{eV}$ below that of Se, producing an even larger cliff offset than the $\mathrm{ZnMgO}$. This is consistent with the lower $V_{\mathrm{OC}}$ and lower performance of devices fabricated with $\mathrm{TiO}_{2}$ as a buffer material.

Device characterization. Table 1 shows a comparison between the three device structures from this work: a $\mathrm{FTO} / \mathrm{TiO}_{2} / \mathrm{Se} / \mathrm{Au}$ device-similar to the previous $5.0 \%$ champion device ${ }^{6}$, an improved high-work-function back contact $\mathrm{FTO} / \mathrm{TiO}_{2} / \mathrm{Se} / \mathrm{MoO}_{x} /$ $\mathrm{Au}$ device, and finally an optimized n-type $\mathrm{ZnMgO}$ buffer FTO/ $\mathrm{ZnMgO} / \mathrm{Se} / \mathrm{MoO}_{x} / \mathrm{Au}$ device. Progressive improvement in performance is observed first with the introduction of $\mathrm{MoO}_{x}$, resulting in improved fill factor from 50.5 to $60.6 \%$ and $V_{\mathrm{OC}}$ enhancement from 728 to $866 \mathrm{mV}$. The introduction of higher band gap $\mathrm{ZnMgO}$ produced additional $100 \mathrm{mV}$ increase in $V_{\mathrm{OC}}$ and $3 \%$ increase in fill factor.

The best performing $\mathrm{FTO} / \mathrm{ZMO} / \mathrm{Se} / \mathrm{MoO}_{x} / \mathrm{Au}$ device had approximate efficiency of $6.5 \%$ with a $V_{\text {OC }}$ of $969 \mathrm{mV}$, fill factor of $63.4 \%$ and $J_{S C}$ of $10.6 \mathrm{~mA} \mathrm{~cm}^{-2}$. The $J_{\mathrm{SC}}$ values were calibrated with EQE measurement (Fig. 2d) in order to eliminate any error due to solar simulator spectral mismatch which can have outsize effects on high- $E_{\mathrm{g}}$ solar cells. This should also eliminate internal reflection from outside the cell area known to be a common issue in superstrate solar cells ${ }^{34}$. The average efficiency of eight cells from the same batch was $6.2 \%$ with a standard deviation of $0.28 \%$. The feasibility of larger cells, was also demonstrated with cell areas $\sim 1 / 4 \mathrm{~cm}^{2}$. These cells demonstrated generally comparable performance to the small dot cells which suggests reasonable device uniformity is achieved. The device statistics comparing small and large cells is summarized in Supplementary Table 1 and full device data is shown in Supplementary Fig. 4. Many Se devices exhibit slight hysteresis resulting in about $6-7 \%$ difference in the maximum power point depending on the scan direction (Supplementary Fig. 5). Slower scans also produce decrease in efficiency but proper interpretation would require modified constant-temperature measurement setup to mitigate the concurrent sample warming. Hysteresis is not common in chalcogenide absorbers and its origin as well as ways to address it are under investigation.

Further gains in $J_{\mathrm{sc}}$ should be readily achievable with improving transparent conductive oxide (TCO) and adding an appropriate anti-reflective coating. In particular the FTO used in this study which has $80-82 \%$ visible transparency specification was measured via UV-vis to transmit only $72 \%$ of the above the band-gap photons in the AM1.5 G spectrum $(280-635 \mathrm{~nm})$. While this transmittance measurement may overstate the 
a
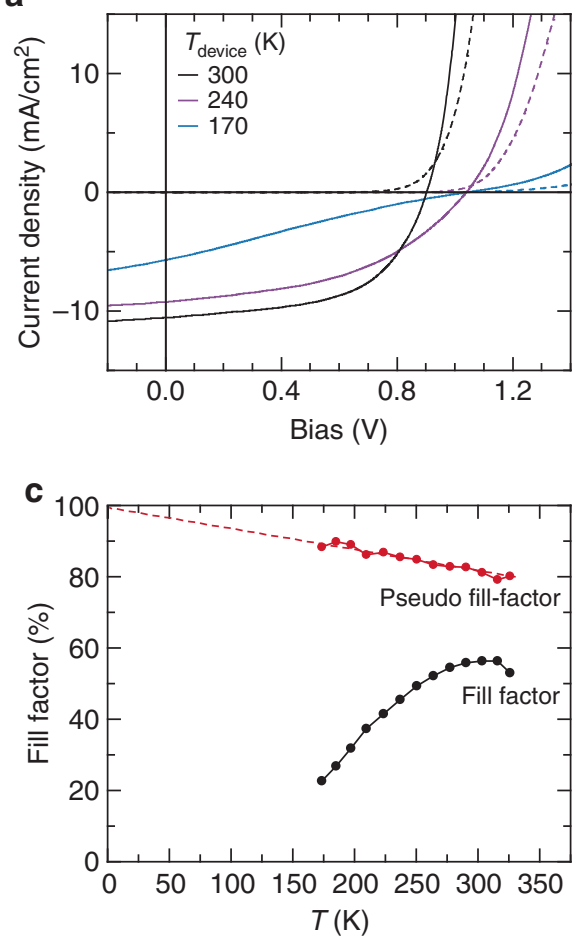

e

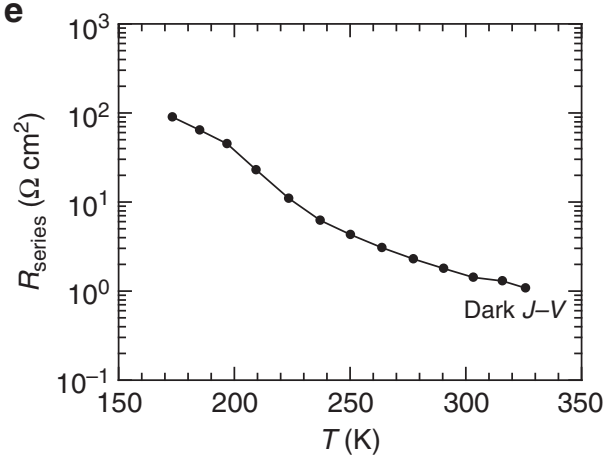

b

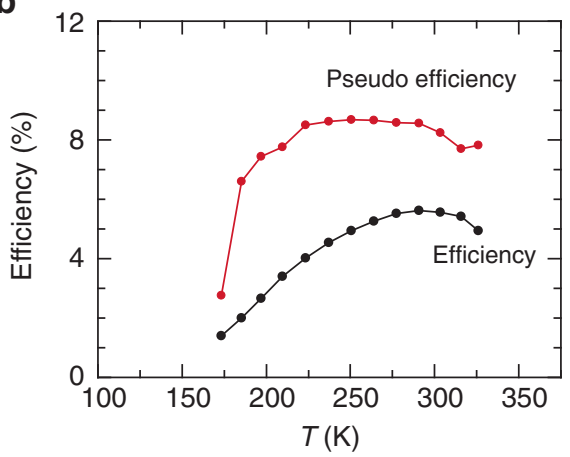

d

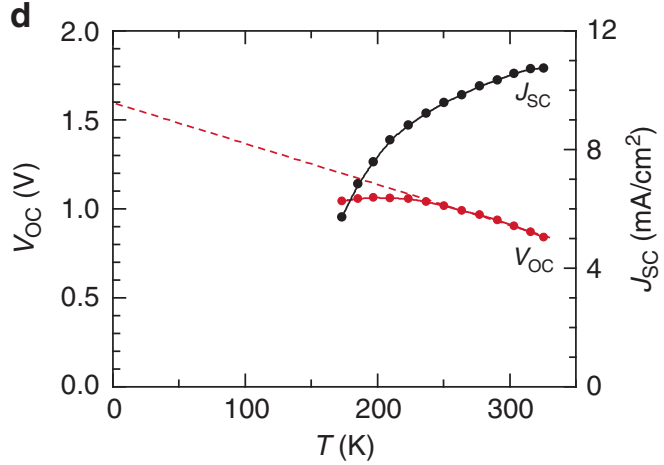

f

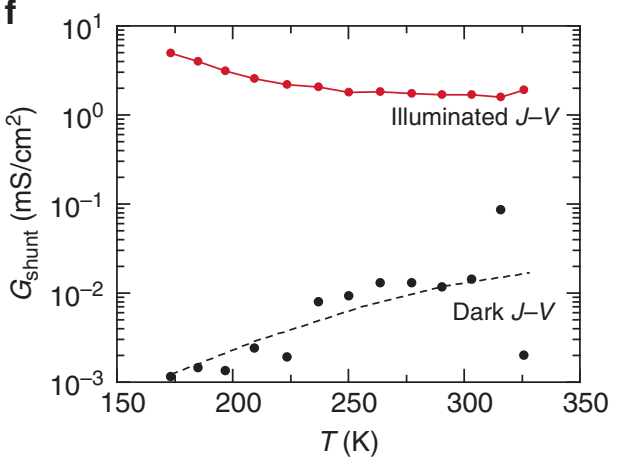

Fig. 5 Temperature-dependent $J-V$ characteristics of the $\mathrm{SnO}_{2}: \mathrm{F} / \mathrm{ZnMgO} / \mathrm{Se} / \mathrm{MoO}_{x} / \mathrm{Au}$ device. a Current-voltage ( $\left.J-V\right)$ plots under $1-\mathrm{Sun}$ illuminated (solid line) and dark (dashed line) conditions measured at the device temperature of $300^{\circ} \mathrm{K}$ (black), $240^{\circ} \mathrm{K}$ (purple), and $170{ }^{\circ} \mathrm{K}$ (blue). b Efficiency (black) and pseudo-efficiency (red) plots. c Fill factor (black) and pseudo-fill-factor (red). The pseudo-efficiency and pseudo-fill-factor were extracted from the short circuit current $\left(J_{\mathrm{SC}}\right)$-open-circuit voltage $\left(V_{\mathrm{OC}}\right)$ measurements under various illumination intensities. $\mathbf{d} J_{\mathrm{SC}}\left(\right.$ black) and $V_{\mathrm{OC}}($ red $)$. e Series resistance $\left(R_{\mathrm{S}}\right)$ extracted from dark $J-V$ measurements. f Shunt conductance $\left(G_{\mathrm{sh}}\right)$ extracted from the illuminated (red) and dark (black) J-V measurements

absorption losses in the system, it still can be surmised to account for a large portion of the EQE loss at lower wavelengths.

We extracted the one-diode parameters (ideality factor $n_{1}$, reverse saturation current $J_{0}$, series resistance $R_{\mathrm{S}}$ and shunt conductance $G_{\text {sh }}$ ) to elucidate the loss mechanisms in this device. We used curve fitting technique based on Lambert-W function as described in ref. ${ }^{35}$ which yields a very good fit. The theoretical SQ limit for a solar cell with $1.95 \mathrm{eV} E_{\mathrm{g}}$ absorber solar are shown at the bottom row of Table 1. These limits are calculated under 1-Sun (AM1.5 G, $100 \mathrm{~mW} \mathrm{~cm}^{-2}$ ) with assumptions described in refs. ${ }^{36,37}$. We observe that even though the $V_{\text {OC }}$ for our champion cell is high, it is significantly lower than its theoretical SQ-limit $V_{\text {OC }}$ of $1650 \mathrm{mV}$. This $V_{\text {OC }}$ deficit (i.e., $E_{\mathrm{g}} / q-V_{\mathrm{OC}}$, where $q$ is the electron charge) of $981 \mathrm{mV}$ shows there is significant potential for improvement. The second problem is the fill-factor (FF) which is about two thirds of the value achievable in the SQ limit. This is mostly attributed to the high ideality factor $\left(n_{1}\right)$ and high $G_{\text {sh }}$ under light. The high $n_{1}$, larger than 2 , suggests several possible factors such as severe recombination in the space charge region, buffer/absorber interface recombination commonly found in heterostructure or tunneling enhanced recombination ${ }^{38}$. Note that the shunt conductance in the dark $\left(G_{\text {sh,Dark }}=1.58 \times 10^{-11} \mathrm{~S} \mathrm{~cm}^{-2}\right)$ is very low indicating no physical shunt or leakage problem across the device, however the light shunt conductance $\left(G_{\text {sh,Light }}\right)$ is higher than the dark indicating voltage-dependent collection-efficiency problem $^{37}$. This problem occurs due to short minority carrier collection length which is caused by high recombination and resulting low minority carrier lifetimes. In this situation, increasing the forward bias will reduce the space charge region and thus the carrier collection significantly-as the collection due to diffusion is minimal. This results in a positive slope near $V=0 \mathrm{~V}$ or higher shunt conductance under light $\left(G_{\text {sh,Light }}\right)$. The series resistance under light is small $\left(<1 \Omega \mathrm{cm}^{2}\right)$ indicating low resistance from top and bottom contacts to the device.

We performed temperature-dependent study of a device similar to the champion Se device $\left(\mathrm{ZnMgO} / \mathrm{Se} / \mathrm{MoO}_{x} / \mathrm{Au}\right)$ on a liquid-nitrogen cooled cryostat under 1-Sun illumination. The efficiency $5.6 \%$ at $25^{\circ} \mathrm{C}$ of this device as measured in the cryostat 
station is about $1 \%$ (absolute) lower than typical probe stage readings with a lower $\mathrm{FF}$ due to a non-ideal contact in our cryostat setup. The efficiency and pseudo-efficiency (the expected in the absence of series resistance, efficiency derived from the $J_{\mathrm{SC}^{-}}$ $V_{\mathrm{OC}}$ measurement under various illumination intensities) is plotted in Fig. 5. We observe that as the temperature decreases, the efficiency slightly increases and then drops monotonically. The drop in efficiency begins at a relatively high temperature $\left(280^{\circ} \mathrm{K}\right)$. This behavior is unlike most other high performance solar cells where higher efficiency occurs down to lower temperatures $\left(100^{\circ} \mathrm{K}\right)$ before the efficiency crashes ${ }^{39}$. Among possible factor for this behavior is the carrier freeze-out effect that occurs in materials with very deep impurity level and increasing blocking transport behavior at the interfaces (e.g., buffer/absorber or absorber/back contact) which easily occurs in low carrier density material. The dominant contributor to the temperaturedependent efficiency behavior is the fill-factor behavior vs. temperature as will be discussed later.

Another important observation can be obtained from the $V_{\mathrm{OC}}$ and $J_{\mathrm{SC}}$ plot in Fig. 5b. The $V_{\mathrm{OC}}$ plot shows the usual initial increase at low temperature, which is expected as recombination is reduced at lower temperatures, decreasing the dark saturation current. However below $220^{\circ} \mathrm{K}$ the $V_{\text {OC }}$ starts to level off. This behavior has been observed in samples with deficient carriers as the device can no longer sustain high $V_{\mathrm{OC}}{ }^{40,41}$. This fact gives another evidence for the freeze-out effect in this device at low temperature. The $0{ }^{\circ} \mathrm{K}$ intercept of the $V_{\mathrm{OC}}$ points to $1.6 \mathrm{eV}$ is consistent with the cliff expected at the $\mathrm{ZnMgO} / \mathrm{Se}$ interface from fs-UPS measurement, still far below the band gap of $1.95 \mathrm{eV}$. The measurements suggest that interface recombination is a pre-dominant factor for limiting $V_{\mathrm{OC}}$ in this device. The $J_{\mathrm{SC}}$ also shows monotonically decreasing behavior at low temperature. Normally in an ideal solar cell, $J_{\mathrm{SC}}$ only changes a little with respect to temperature. The marked decrease in the $J_{S C}$ here is due to the significant increase in series resistance $\left(R_{\mathrm{S}}\right)$ at low temperatures that distort the $J-V$ curve and lower its value at low temperature. This occurs approximately when $R_{\mathrm{S}}$ is larger than $V_{\mathrm{oc}} / J_{\mathrm{sc}}$. The fill factor vs. temperature profile is determinant factor in the efficiency behavior, i.e., it increases slightly but quenches at low temperature. Specifically, the quench at low temperature is attributed to the increase in bias dependent collection limitation (responsible for very high shunt conductance $\mathrm{G}_{\text {sh,light }}$ ) and increase in series resistance $R_{\mathrm{S}}$ as shown in Fig. $5 \mathrm{e}, \mathrm{f}$. The dark $R_{\mathrm{S}}$ shows increasing behavior at low temperature that could originate from the carrier freeze-out effect of the absorber or increasing non-ohmic contact between the absorber and back contact. Finally, in Fig. 5f, we show that $G_{\text {sh,Light }}$ is always larger than the $G_{\text {sh,Dark }}$ due to the voltage dependent collection efficiency problem as described earlier.

\section{Discussion}

We have demonstrated a substantial efficiency improvement for Se photovoltaics, 30 years after the last efficiency milestone was set, and further outlined key areas for future improvements. Three areas of focus may offer particularly large improvements. First, optimizing the buffer layer to reduce the cliff at interface should significantly improve $V_{\mathrm{OC}}$ as well as fill factor. Second, increasing lifetime and/or increasing the depletion width should reduce the voltage-dependent collection thus improving $\mathrm{FF}$ and further improving $V_{\mathrm{OC}}$. Lastly, higher-transmission TCO, an anti-reflective coating, and improved reflection of the back contact coupled with thickness re-optimization is expected to boost $J_{\mathrm{SC}}$ by increasing absorbed photons. Optimization of TCO alone may allow $>10 \%$ increase in $J_{\text {SC }}$ due to the high absorbance at low wavelengths. Additional strategies such as increasing carrier density of the Se absorber through doping may offer a further means to improve the $V_{\mathrm{OC}}$.
In addition to higher performance potential, other qualities make Se an attractive alternative candidate for a high-band-gap absorber. For practical applications, a simple and inexpensive fabrication process, lack of highly toxic elements such as $\mathrm{Cd}$ and $\mathrm{Pb}$, and stability upon prolonged storage and air exposure for these devices (for the duration of our testing) are significant advantages. More detailed stability testing under real operation condition is required. In addition, due to the ultra-thin layers, material usage is minimal and therefore material availability and raw material costs are not practical concerns. The potential to scale production to large-scale manufacturing is aided by fast and low-temperature deposition methods which also enable the use of plastic and flexible substrates or roll-to-roll fabrication. The high $E_{\mathrm{g}}$ makes Se attractive as a top cell in multi-junction devices and the low processing temperature processing could allow drop-in compatibility with crystalline $\mathrm{Si}$ or CIGS thin film manufacturing. In addition, the high-band gap shows strong match as a single junction for the indoor lightning spectrum (increased blue range) ${ }^{6}$, coupled with high $V_{\mathrm{OC}}$ and simple fabrication offers a strong fit for consumer electronics power solutions including autonomous sensors, wearable and internet-of-things devices ${ }^{42}$. After more than three decades with no improvements and little research attention, selenium solar cells may deserve a second look.

\section{Methods}

Solar cell fabrication. Unless otherwise specified all materials were purchased from Sigma Aldrich. Fluorine-doped Tin Oxide glass ( $7 \Omega$ per square, $80-82 \%$ visible light transmittance) was washed consecutively with acetone, isopropanol and ammonium hydroxide. $\mathrm{TiO}_{2}$ buffers with thickness about 30-50 nm were airsprayed from a 10 vol\% each: titanium di-isopropoxide and acetylacetone solution in ethanol on a substrate preheated at $500{ }^{\circ} \mathrm{C}$ followed by annealing at $540{ }^{\circ} \mathrm{C}$ for $10 \mathrm{~min}$. ZnMgO buffer layers were deposited by the simultaneous radio-frequency sputtering from $\mathrm{ZnO}$ (99.999\%) and $\mathrm{MgO}$ (99.95\%) ceramic targets (Kurt Lesker) mounted on adjacent guns in a 5-source CMS-18 sputtering system (Kurt J. Lesker). An 8 " sample holder was used. For combinatorial studies the sample position was indexed and no rotation was used. For baseline process rotation was used and the deposition rate was $\sim 0.5 \mathrm{~nm} \mathrm{~min}{ }^{-1}$. No temperature control was used for the samples during sputtering and evaporation. All thermal evaporations were done from resistively heated alumina crucibles. Te and Se films were deposited by using a custom-built $8^{\prime \prime}$ diameter, $12^{\prime \prime}$ throwing distance thermal evaporation chamber under a pressure of $5 \times 10^{-6}$ Torr and approximate rate of $20 \mathrm{~nm} \mathrm{~min}^{-1}$. Final devices were fabricated by thermal evaporation of $\mathrm{MoO}_{3}$ (99.5\% Alfa Aesar, $\left.4 \mathrm{~nm} \mathrm{~min}{ }^{-1}\right)$ and $\mathrm{Au}\left(99.99 \%\right.$, Alfa Aesar, $\left.10 \mathrm{~nm} \mathrm{~min}^{-1}\right)$, on the top of Se using dot masks. Deposition rates were controlled with INFICON quartz crystal monitor and manual power adjustment. All annealing was performed by placing samples on a pre-heated aluminum hot plate for $2 \mathrm{~min}$ and temperature calibration was performed with a thermocouple glued to a dummy sample. Cell area was confirmed via microscope and LBIC (Light-beam induced current) measurement to be equal to back contact mask size of $2.27 \mathrm{~mm}^{2}$.

Characterization. $J-V$ characteristics of the devices were measured by using a Keithley 2400 source-meter. A $6 \times 6$ in $^{2}$ beam solar simulator equipped with a $1000 \mathrm{~W}$ Xe arc lamp with an AM1.5 G filter (Newport). In order to work in superstrate configuration we used double perpendicular aluminum-coated mirror reflector adapter calibrated to 1-Sun illumination condition $\left(100 \mathrm{~mW} \mathrm{~cm}^{-2}\right)$ with $\mathrm{n}$ NREL-traceable silicon reference cell with a BK-7 window was used to calibrate the illumination intensity. Despite calibrated light intensity, a spectral mismatch using the superstrate test setup was noted which resulted in a slight increase in blue light which can results in overstated $J_{\mathrm{SC}}$ for high $-E_{\mathrm{g}}$ absorbers. To correct for this, as well as possible internal glass reflection in superstrate configuration the current values in this paper were adjusted down to match a calibrated EQE value. Standard voltage scans were done at a rate of $1 \mathrm{~V} \mathrm{~s}^{-1}$ backward direction in air at room temperature.

The temperature-dependent $J-V$ measurement was performed in a nitrogenfilled chamber using a liquid-nitrogen cryostat with IBM-PVX software system ${ }^{43}$ with rotating neutral density filter for integrated $J_{\mathrm{SC}}-V_{\mathrm{OC}}$ measurement for pseudoefficiency and pseudo-fill-factor measurement. Two temperature sensors are used: one on the cold stage for the closed-loop temperature control and second clamped on the device to sense the device temperature. The one-diode model parameters (ideality factor $n_{1}$, ideality factor $J_{0}$, series resistance $R_{\mathrm{S}}$ and shunt conductance $G_{\mathrm{sh}}$ ) are determined using fitting method based on Lambert-W function ${ }^{35}$. The EQE of the device was measured by using a QEX10 (PV Measurements) calibrated with a NIST-certified Si photodiode. Optical absorption spectra were measured by using a Lambda 950 UV-vis spectrometer (Perkin Elmer). Raman spectra were measured ex situ with a $15 \mathrm{~mW} 532 \mathrm{~nm}$ laser on a Horiba LabRAM system using a $\times 10$ confocal lens and an $1800 \mathrm{~g} \mathrm{~mm}^{-1}$ diffraction grating. A neutral density filter 
of ND 4.0 was inserted to mitigate photo-bleaching of the samples. A long exposure time of $100 \mathrm{~s}$ was used with the lower magnification to improve signal to noise ratio. Data were smoothed with a five-point moving window FFT filter. For fs-UPS measurements, a single $800 \mathrm{~nm}$ pulse from an amplified fs laser is split into synchronized pump and probe legs. The $800 \mathrm{~nm}$ pump pulse is frequency doubled to $400 \mathrm{~nm}(3.1 \mathrm{eV}$ per photon) and used to excite a dense electron hole population within the Se absorber, flattening the bands. The $800 \mathrm{~nm}$ probe pulse is converted to $26.35 \mathrm{eV}$ via high harmonic generation in a gas and is used to generate the UPS spectra. In this manner, the valence band edges can be determined under flat band conditions and accurate offsets can be determined.

Data availability. The data that support the findings of this study are available from the corresponding author upon request.

Received: 18 October 2016 Accepted: 11 July 2017

Published online: 25 September 2017

\section{References}

1. Smith, W. Effect of light on selenium during the passage of an electric current. Nature 7, 303 (1873).

2. Fritts, C. E. On a new form of selenium cell, and some electrical discoveries made by its use. Am. J. Sci. 26, 465-472 (1883).

3. Einstein, A. Ueber einen die Erzeugung und Verwandlung des Lichtes betreffenden heuristichen Gesichtspunkt. Ann. Phys. 17, 132-148 (1905).

4. Einstein, A. \& Bucky, G. Light intensity self-adjusting camera. US patent US2058562 A (1936).

5. Bidwell, S. Tele-photography. Nature 23, 344-346 (1881).

6. Green, M. A. Silicon photovoltaic modules: a brief history of the first 50 years. Prog. Photovolt. Res. Appl. 13, 447-455 (2005).

7. Green, M. A. et al. Solar cell efficiency tables (version 49). Prog. Photovolt. Res. Appl. 25, 3-13 (2017).

8. SunPower ${ }^{\circledR}$. Solar panel again raises the bar in efficiency-Jun 27, 2016. Available at: http://newsroom.sunpower.com/2016-06-27-SunPower-SolarPanel-Again-Raises-the-Bar-in-Efficiency (SunPower Corporation, 2016).

9. Fu, R. et al. US solar photovoltaic system cost benchmark: Q1 2016. Technical Report NREL/TP-6A20-66532 (NREL, 2016).

10. Werner, J. et al. Efficient monolithic perovskite/silicon tandem solar cell with cell area $>1 \mathrm{~cm}^{2}$. J. Phys. Chem. Lett. 7, 161-166 (2016).

11. Todorov, T. et al. Monolithic perovskite-CIGS tandem solar cells via in situ band gap engineering. Adv. Energy Mater. 5, 1500799 (2015).

12. Todorov, T., Gershon, T., Gunawan, O., Sturdevant, C. \& Guha, S. Perovskitekesterite monolithic tandem solar cells with high open-circuit voltage. Appl. Phys. Lett. 105, 173902 (2014).

13. Eperon, G. E. et al. Perovskite-perovskite tandem photovoltaics with optimized bandgaps. Science 354, 861-865 (2016).

14. Bhatnagar, A. K., Reddy, K. V. \& Srivastava, V. Optical energy gap of amorphous selenium: effect of annealing. J. Appl. Phys. 18, L149-L153 (1985).

15. Tutihasi, S. \& Chen, I. Optical properties and band structure of trigonal selenium. Phys. Rev. 158, 623 (1967).

16. Nakada, T. \& Kunioka, A. Polycrystalline thin-film $\mathrm{TiO}_{2} / \mathrm{Se}$ solar cells. Jpn. J. Appl. Phys. 24, L536-L538 (1985).

17. Luo, S. \& Daoud, W. A. Recent progress in organic-inorganic halide perovskite solar cells: mechanisms and material design. J. Mater. Chem. A 3, 8992-9010 (2015).

18. Wang, K. et al. Selenium as a photoabsorber for inorganic-organic hybrid solar cells. Phys. Chem. Chem. Phys. 16, 23316-23319 (2014).

19. Zhu, M. et al. Solution-processed air-stable mesoscopic selenium solar cells. ACS Energy Lett. 1, 469-473 (2016).

20. Sun, Y. et al. Efficient, air-stable bulk heterojunction polymer solar cells using $\mathrm{MoO}_{x}$ as the anode interfacial layer. Adv. Mater. 23, 2226-2230 (2011).

21. Yang, T. et al. Polymer solar cells with a low-temperature-annealed sol-gelderived $\mathrm{MoO}_{x}$ film as a hole extraction layer. Adv. Energy Mater. 2, 523-527 (2012).

22. Paudel, N., Compaan, A. \& Yan, Y. Sputtered CdS/CdTe solar cells with $\mathrm{MoO}_{3-x} / \mathrm{Au}$ back contacts. Sol. Energy Mater. Sol. Cells 113, 26-30 (2013).

23. Hariskos, D. et al. The $\mathrm{Zn}(\mathrm{S}, \mathrm{O}, \mathrm{OH}) / \mathrm{ZnMgO}$ buffer in thin-film $\mathrm{Cu}(\mathrm{In}, \mathrm{Ga})(\mathrm{Se}$, $\mathrm{S})_{2}$-based solar cells part II: magnetron sputtering of the $\mathrm{ZnMgO}$ buffer layer for in-line co-evaporated $\mathrm{Cu}(\mathrm{In}, \mathrm{Ga}) \mathrm{Se}_{2}$ solar cells. Prog. Photovolt. 17, 479-488 (2009).

24. Jeon, N. J. et al. Solvent engineering for high-performance inorganic-organic hybrid perovskite solar cells. Nat. Mater. 13, 897-903 (2014).

25. Gunawan, O., Virgus, Y. \& Tai, K. F. A parallel dipole line system. Appl. Phys. Lett. 106, 062407 (2015).

26. Brenner, T. M. et al. Are mobilities in hybrid organic-inorganic halide perovskites actually "high"? J. Phys. Chem. Lett. 6, 4754-4757 (2015).

27. Cattin, L., Morsli, M. \& Bernède, J. C. Improvement in the lifetime of planar organic photovoltaic cells through the introduction of $\mathrm{MoO}_{3}$ into their cathode buffer layers. Electronics 3, 122-131 (2014).
28. Minemoto, T. et al. Theoretical analysis of the effect of conduction band offset of window/CIS layers on performance of CIS solar cells using device simulation. Sol. Energy Mater. Sol. Cell 67, 83-88 (2001).

29. Lee, C.-S., Larina, L., Shin, Y.-M., Al-Ammar, E. A. \& Ahn, B. T. Design of energy band alignment at the $\mathrm{Zn}_{1-x} \mathrm{Mg}_{x} \mathrm{O} / \mathrm{Cu}(\mathrm{In}, \mathrm{Ga}) \mathrm{Se}_{2}$ interface for Cd-free $\mathrm{Cu}(\mathrm{In}, \mathrm{Ga}) \mathrm{Se}_{2}$ solar cells. Phys. Chem. Chem. Phys. 14, 4789-4795 (2012).

30. Olson, D. C. et al. Band-offset engineering for enhanced open-circuit voltage in polymer-oxide hybrid solar cells. Adv. Funct. Mater. 17, 264-269 (2007).

31. Ding, S. et al. Combinatorial development of bulk metallic glasses. Nat. Mater. 13, 494-500 (2014).

32. Haight, R. et al. Band alignment at the $\mathrm{Cu}_{2} \mathrm{ZnSnSxSe}[1-x]_{4} / \mathrm{CdS}$ interface. Appl. Phys. Lett. 98, 253502 (2011)

33. Barkhouse, A. R. et al. Cd-free buffer layer materials on $\mathrm{Cu}_{2} \mathrm{ZnSn}\left(\mathrm{S}_{x} \mathrm{Se}_{1-x}\right)_{4}$ : band alignments with $\mathrm{ZnO}, \mathrm{ZnS}$, and $\mathrm{In}_{2} \mathrm{~S}_{3}$. Appl. Phys. Lett. 100, 193904 (2012).

34. Snaith, $\mathrm{H}$. The perils of solar cell efficiency measurements. Nat. Photonics 6 , 337-340 (2012).

35. Zhang, C., Zhang, J., Hao, Y., Lin, Z. \& Zhu, C. A simple and efficient solar cell parameter extraction method from a single current-voltage curve. J. Appl. Phys. 110, 064504 (2011).

36. Rau, U. \& Werner, J. H. Radiative efficiency limits of solar cells with lateral band-gap fluctuations. Appl. Phys. Lett. 84, 3735 (2004).

37. Hegedus, S. S. \& Shafarman, W. N. Thin-film solar cells: device measurements and analysis. Prog. Photovolt.: Res. Appl. 12, 155-176 (2004).

38. Rau, U. Tunneling-enhanced recombination in $\mathrm{Cu}(\mathrm{In}, \mathrm{Ga})$ Se heterojunction solar cells. Appl. Phys. Lett. 74, 111 (1999).

39. Krustok, J., Josepson, R., Danilson, M. \& Meissner, D. Temperature dependence of $\mathrm{Cu}_{2} \mathrm{ZnSn}\left(\mathrm{Se}_{x} \mathrm{~S}_{1-x}\right)_{4}$ monograin solar cells. Sol. Energy 84, 379 (2010).

40. Gunawan, O., Todorov, T. K. \& Mitzi, D. B. Loss mechanisms in hydrazineprocessed $\mathrm{Cu}_{2} \mathrm{ZnSn}(\mathrm{Se}, \mathrm{S})_{4}$ solar cells. Appl. Phys. Lett. 97, 233506 (2010).

41. Gunawan, O., Gokmen, T. \& Mitzi, D. B. Suns- $V_{\mathrm{OC}}$ characteristics of high performance kesterite solar cells. J. Appl. Phys. 116, 084504 (2014).

42. Haight, R., Haensch, W. \& Friedman, D. Solar-powering the internet of things. Science 353, 124-125 (2016).

43. Gunawan, O. \& Lei, B. Solar cell characterization system with an automated continuous neutral density filter. US patent 8797058 (2014).

\section{Acknowledgements}

We thank Ravin Mankad for his valuable help in sample fabrication and measuremen and Jay S. Chey for setting up the $\mathrm{ZnO}-\mathrm{MgO}$ sputtering process.

\section{Author contributions}

T.K.T., S.S., and T.S.G. conceived and designed the experiments. T.K.T., S.S. and D.M.B. conducted the experiments. O.G. performed temperature dependent and hall measurements and analyzed the device parameters. D.M.B., Y.S.L. and T.S.G. performed optical and EQE measurements. K.W.B. performed Raman measurements. P.D.A. assisted in IV measurement. T.K.T., D.M.B., Y.S.L., O.G. and R.H. wrote the manuscript. All authors participated in discussion of the results and the manuscript.

\section{Additional information}

Supplementary Information accompanies this paper at doi:10.1038/s41467-017-00582-9.

Competing interests: The authors declare no competing financial interests.

Reprints and permission information is available online at http://npg.nature.com/ reprintsandpermissions/

Publisher's note: Springer Nature remains neutral with regard to jurisdictional claims in published maps and institutional affiliations.

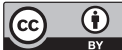

Open Access This article is licensed under a Creative Commons Attribution 4.0 International License, which permits use, sharing, adaptation, distribution and reproduction in any medium or format, as long as you give appropriate credit to the original author(s) and the source, provide a link to the Creative Commons license, and indicate if changes were made. The images or other third party material in this article are included in the article's Creative Commons license, unless indicated otherwise in a credit line to the material. If material is not included in the article's Creative Commons license and your intended use is not permitted by statutory regulation or exceeds the permitted use, you will need to obtain permission directly from the copyright holder. To view a copy of this license, visit http://creativecommons.org/ licenses/by/4.0/.
}

(C) The Author(s) 2017 